\title{
Cytotoxicity of tubeimoside I in human choriocarcinoma JEG-3 cells by induction of cytochrome c release and apoptosis via the mitochondrial-related signaling pathway
}

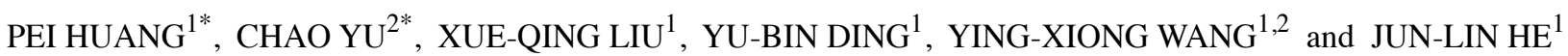 \\ ${ }^{1}$ Laboratory of Reproductive Biology, School of Public Health and ${ }^{2}$ Institute of Life Science, \\ Chongqing Medical University, Chongqing 400016, P.R. China
}

Received April 12, 2011; Accepted May 27, 2011

DOI: $10.3892 / \mathrm{ijmm} .2011 .727$

\begin{abstract}
Mitochondria play important roles in the intrinsic pathways that trigger apoptosis. Anticancer chemotherapies eliminate cancer cells mainly through the induction of apoptosis. In the present study, we investigated the mechanism of the cytotoxic effects of tubeimoside I (TBMS1) on the human choriocarcinoma cell line (JEG-3). Choriocarcinoma is one of the most common malignant tumors in the reproductive system. TBMS1, a triterpenoid saponin, isolated from the tubers of Bolbostemma paniculatum (Maxim) Franquet (Cucurbitaceae), showed potent antitumor effects. However, the potential roles of TBMS1 in the treatment of choriocarcinoma remain unknown. In the present study, we examined the effects of TBMS1 on JEG-3 cells. TBMS1 displayed strong growth inhibitory effects on JEG-3 cell growth. In addition, TBMS1 treatment with TBMS1 led to marked cell apoptosis, significant cell cycle arrest at $\mathrm{G}_{2}$ phase and decrease in mitochondrial transmembrane potential $(\Delta \Psi \mathrm{m})$. Cytochrome $\mathrm{c}$ was released from the mitochondria and caspase- 3 expression was enhanced. Furthermore, TBMS1 induced the up-regulation of Bcl-2 asso-
\end{abstract}

Correspondence to: Dr Jun-Lin He, Laboratory of Reproductive Biology, School of Public Health, Chongqing Medical University, 1 Yi Xue Yuan Road, Box 197, Chongqing 400016, P.R. China

E-mail: hejunlin_11@yahoo.com.cn

${ }^{*}$ Contributed equally

Abbreviations: JEG-3 cells, human choriocarcinoma cells; TBMS1, tubeimoside I; MTT, 3-(4,5-dimethylthiazol-2-yl)-2,5-diphenyltetrazolium bromide; $\Delta \Psi \mathrm{m}$, mitochondrial transmembrane potential; mPTP, mitochondrial permeability transition pore; DMSO, dimethyl sulphoxide; Bax, Bcl-2 associated $\mathrm{X}$ protein; $\mathrm{Bcl}-2$, B cell lymphoma/ leukemia-2; NF- $\mathrm{B}$, nuclear factor- $-\mathrm{B}$; p38/MAPK, p38 mitogenactivated protein kinase; ERK, extracellular signal-regulated kinases; Akt, protein kinase B; IMM, inner mitochondrial membrane; OMM, outer mitochondrial membrane

Key words: tubeimoside I, apoptosis, mitochondria, human choriocarcinoma cells ciated $\mathrm{X}$ protein (Bax) expression, down-regulation of $\mathrm{Bcl}-2$ expression, inhibition of nuclear factor- $\mathrm{\kappa}-\mathrm{B}(\mathrm{NF}-\mathrm{\kappa B})$ function and impacted the phosphorylation of $\mathrm{p} 38$ mitogen-activated protein kinase (p38/MAPK), extracellular signal-regulated kinases (ERK)1/2 and protein kinase B (Akt). Taken together, our findings suggest that TBMS1 is an efficient apoptosisinducing agent for choriocarcinoma cells, which exerts its effects, at least partially, by the induction of mitochondrial dysfunction and regulation of the p38/MAPK, ERK1/2 and PI3K/Akt signaling pathways.

\section{Introduction}

Apoptosis, a mechanism of programmed cell death, is strictly linked to the pathogenesis of many human diseases, including neoplastic, neurodegenerative or cardiovascular diseases (1). It usually occurs through extrinsic or intrinsic apoptotic pathways. The latter is assumed to initiate in the mitochondria, which has been suggested to play a key role in the induction of apoptosis in several cell types $(2,3)$. Alterations of mitochondrial architecture, membrane potential, and oxidative capacity are directly elicited when the cell receives injury or stress stimulation. To maintain mitochondrial function, membrane potential may have a dramatic influence on cardiomyocyte energy production and ultimately the survival of an individual cell (4). A major player in this process is the mitochondrial permeability transition pore (mPTP), which is located at the contact sites between the inner and outer mitochondrial membranes (OMMs). Opening of the mPTP is most likely regulated by members of the B cell lymphoma/leukemia-2 (Bcl-2) family. The different anti- and pro-apoptotic members of this family form a highly selective network of functional interactions that involves the permeabilization of the mitochondrial membrane and results in the release of pro-apoptotic factors such as cytochrome $\mathrm{c}$ from the mitochondria, followed by a caspase-mediated effector phase $(3,5,6)$.

Anticancer chemotherapies mainly exert their elimination of cancer cells by apoptotic process. Tubeimoside I (TBMS1), a bisdesmosidic triterpenoid saponin isolated from Bolbostemma paniculatum (Maxim) Franquet (Cucurbitaceae), has sugar chains that are connected with 3-hydroxy-3-methylglutaric acid to form a unique macrocyclic structure (Fig. 1) (7). 


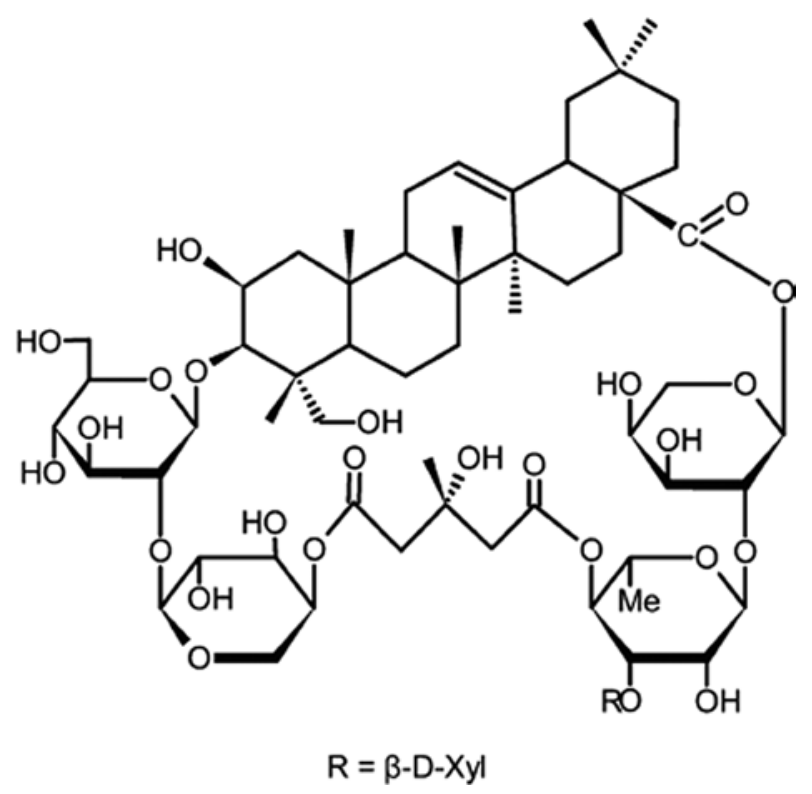

Figure 1. Chemical structure of tubeimoside I (TBMS1).

Previous studies demonstrated that TBMS1 exhibits a variety of biological activities including potent antitumor properties in a variety of cancer types $(8,9)$, including human low differentiated nasopharyngeal carcinoma (CNE-2Z) cells (10), human promyelocytic leukemia (HL-60) cells (11) and human uterine cervix cancer (HeLa) cells (12). These anticancer activities of TBMS1 have been linked to its ability to directly trigger mitochondrial membrane permeabilization. However, the detailed mechanisms and intracellular targets of TBMS1 in inducing cell death remain to be elucidated. Whether or not TBMS1 is effective on choriocarcinoma is still unknown.

To determine whether TBMS1-induced apoptosis in choriocarcinoma cells is mediated through the mitochondria dysfunction pathway, we chose the human choriocarcinoma cell line JEG-3 as an in vitro model to explore the effects of TBMS1 on choriocarcinoma cell growth and apoptosis. Our findings suggest, for the first time, that TBMS1 is an efficient apoptotic agent against choriocarcinoma cells, which is, at least partly, mediated by attenuating nuclear factor- $\kappa-\mathrm{B}$ (NF- $\mathrm{\kappa B}$ ) activation and translocation through $\mathrm{p} 38$ mitogen-activated protein kinase (p38/MAPK), extracellular signal-regulated kinases (ERK)1/2 and PI3K/protein kinase B (Akt) pathways, breaking the balance of $\mathrm{Bcl}-2$ associated $\mathrm{X}$ protein (Bax)/ $\mathrm{Bcl}-2$ and aggravating mitochondrial dysfunction. Thus, mitochondrion-targeted agents such as TBMS1 hold great promise as novel approaches to treat human cancers.

\section{Materials and methods}

Chemicals and reagents. Dulbecco's modified Eagle's medium (high glucose) and fetal bovine serum were purchased from Gibco (Grand Island, NY, USA). The anti-cytochrome c, antiBcl-2, anti-Bax, anti-caspase- 3 and anti- $\beta$-actin monoclonal antibodies were purchased from Cell Signaling Technology (Beverly, MA, USA). The anti-ERK1/2, anti-p-ERK1/2, anti-p38, anti-p-p38, anti-Akt, anti-p-Akt and anti-NF-кB p65 monoclonal antibodies were purchased from Santa Cruz
Biotechnology (Santa Cruz, CA, USA). TRIzol was obtained from Sangon Biological Engineering Technology and Services (Shanghai, China). The pNF- $\mathrm{B}$ vector was purchased from Beyotime Co., Ltd. (China), and the pRL-TK vector and Dual-Luciferase Reporter Assay System were obtained from Promega (Madison, WI). Lipofectamine ${ }^{\mathrm{TM}} 2000$ was obtained from Invitrogen Life Technologies (Carlsbad, CA, USA). The Annexin V-fluorescein isothiocyanate (FITC) apoptosis detection kit was obtained from Nanjing Key-Gen Biotech Co., Ltd. (Nanjing, China). All other chemicals, including 3-(4,5-dimethylthiazol-2-yl)-2,5-diphenyltetrazolium bromide (MTT), lipophilic cationic dye JC-1, Hoechst 33342, and fluorescent $\mathrm{Ca}^{2+}$-indicator dye were obtained from Sigma (St. Louis, MO, USA). TBMS1, which was extracted by our laboratory, was dissolved in PBS and stored at $-20^{\circ} \mathrm{C}$. Human choriocarcinoma cell line JEG-3 cells were purchased from the State Key Laboratory of Reproductive Biology of the Institute of Zoology at the Chinese Academy of Sciences (CAS) in Beijing, China.

Cell lines and culture conditions. The JEG-3 cell line was maintained in DMEM (high glucose) supplemented with heat-inactivated $10 \%$ fetal bovine serum, $100 \mathrm{U} / \mathrm{ml}$ penicillin, and $100 \mathrm{U} / \mathrm{ml}$ streptomycin in a humidified atmosphere of 5\% $\mathrm{CO}_{2}$ at $37^{\circ} \mathrm{C}$. Exponentially growing cells were used for all the experiments.

Cell viability measurement. Cell viability was assessed by the MTT assay (13). Briefly, JEG-3 cells were seeded in 96-well plates $\left(7.5 \times 10^{3}\right.$ cells/well) and treated with different concentrations of TBMS1 for $24 \mathrm{~h}$. After treatment, cells were washed with PBS and incubated with MTT $(5 \mathrm{mg} / \mathrm{ml})$ in culture medium at $37^{\circ} \mathrm{C}$ for another $3 \mathrm{~h}$. After that, the formazan blue, which formed in cells, was solubilized in $100 \mu \mathrm{l}$ of dimethylsulphoxide (DMSO). The absorption values were measured at a wavelength of $490 \mathrm{~nm}$ using a Sunrise Remote Microplate Reader (Grodig, Austria). The viability of JEG-3 cells in each well was presented as the percentage of control cells.

Flow cytometric evaluation of apoptosis. JEG-3 cells growing in $25-\mathrm{cm}^{2}$ culture flasks were harvested, washed and doublestained by using an Annexin V-FITC apoptosis detection kit. Annexin $\mathrm{V}$ has a strong, $\mathrm{Ca}^{2+}$-dependent affinity for phosphatidylserine (PS), which translocates from the internal to the external surface of the plasma membrane as a probe for detecting apoptosis (14). Cells that have loss of membrane integrity will show red staining (propidium iodide, PI) throughout the nucleus and therefore will be easily distinguished between the early apoptotic, late apoptotic, or necrotic cells. Samples were incubated at room temperature for $15 \mathrm{~min}$ in the dark with Annexin V and PI and quantitatively analyzed by a FACSVantage SE flow cytometer.

Flow cytometry for cell cycle analysis. JEG-3 cells growing in $25-\mathrm{cm}^{2}$ culture flasks were harvested, washed and fixed with ice-cold alcohol (75\%) for more than $24 \mathrm{~h}$. After being washed twice more, cells were incubated with PBS ( $\mathrm{pH} 7.4$ ), containing RNase (5 units) and PI $(50 \mu \mathrm{g} / \mathrm{ml})$, for $15 \mathrm{~min}$ at $37^{\circ} \mathrm{C}$. Flow cytometry was performed using a FACSVantage SE flow cytometer. 
Mitochondrial transmembrane potential $(\Delta \Psi m)$. Changes in $\Delta \Psi_{\mathrm{m}}$ were detected by JC-1 staining $(20 \mu \mathrm{g} / \mathrm{ml})$ for $20 \mathrm{~min}$ at $37^{\circ} \mathrm{C}$. JC-1 fluorescence was measured by a FACSVantage SE flow cytometer with an excitation wavelength of $490 \mathrm{~nm}$ and an emission wavelength of $527 \mathrm{~nm}$.

Intracellular calcium ion measurement. Changes in intracellular calcium ions $\left(\mathrm{Ca}^{2+}\right)_{\text {i }}$ were measured by the calcium probe fluo-3 $(75 \mathrm{mM})$ for $1 \mathrm{~h}$ at $37^{\circ} \mathrm{C}$. Calcium probe fluo-3 fluorescence was measured by a FACSVantage SE flow cytometer with an excitation wavelength of $355 \mathrm{~nm}$ and an emission wavelength of $485 \mathrm{~nm}$.

Imaging of morphological changes. Morphological changes of apoptosis were detected by fluorescence microscopy after staining with Hoechst 33342. Briefly, cells were cultured in 96-well plates to $50 \%$ confluence. Upon the completion of drug treatment, cells were washed with PBS and incubated with Hoechst 33342 at $37^{\circ} \mathrm{C}$ for $20 \mathrm{~min}$, then observed under a Leica DMRX microscope (Wetzlar, Germany).

Confocal fluorescence microscopy. Single-cell observations using a confocal fluorescence microscope with an argon-ion laser and a He-Cd laser were performed by the following procedure. Briefly, cells were cultured in culture dishes to $50 \%$ confluence. Upon the completion of drug treatment, cells were washed with ice-cold PBS and fixed in PBS-buffered $4 \%$ paraformaldehyde at room temperature for $20 \mathrm{~min}$, followed by the incubation with $0.3 \%$ Triton X-100 in PBS for $20 \mathrm{~min}$. Then, cells were blocked with $10 \%$ goat serum for $10 \mathrm{~min}$ and incubated overnight with the rabbit anti-cytochrome $\mathrm{c}$ monoclonal antibodies at $4^{\circ} \mathrm{C}$. Thereafter, the cells were washed with PBS and incubated with fluorescein isothiocyanate (FITC)- labeled rabbit IgG for $1 \mathrm{~h}$. Finally, cells were washed with PBS and incubated with JC-1 $(20 \mu \mathrm{g} / \mathrm{ml})$ for $20 \mathrm{~min}$, then observed under a confocal fluorescence-microscope system (MRC-600, Bio-Rad) with an inverted epifluorescence microscope (Nikon TMD-EFQ). JEG-3 cells were excited at a wavelength of $488 \mathrm{~nm}$ for cytochrome c or a wavelength of $543 \mathrm{~nm}$ for JC-1.

$N F-\kappa B$ reporter assays. JEG-3 cells $\left(6 \times 10^{4}\right)$ were plated in $24-w e l l$ plates and transfected for $4 \mathrm{~h}$ with the NF- $\mathrm{BB}$ plasmid (500 ng, with firefly luciferase) and the pRL-TK plasmid (300 ng, with Renilla luciferase used as internal control for transfection efficiency) using Lipofectamine reagent (Invitrogen). Twenty-four hours after transfection, cells were exposed to TBMS1 $(6 \mu \mathrm{M})$ for an additional $24 \mathrm{~h}$. Luciferase activity was determined using protocols and reagents from Promega. Luciferase activities were calculated and represented as Firefly/Renilla (relative luciferase activity).

Preparations of RNA extraction and reverse transcriptionpolymerase chain reaction ( $R T-P C R)$. Total-RNA was extracted from $1 \times 10^{6}$ cells according to the manufacturer's instructions (15). Reverse transcription was carried out in $10 \mu \mathrm{l}$ of the reaction mixture containing $1 \mu \mathrm{g}$ of total-RNA, $25 \mathrm{pmol}$ of oligo(dt) primer, $10 \mathrm{nmol}$ of dNTP mixture, 20 units of RNase inhibitor and 2.5 units of AMV reverse transcriptase (Bioer, Hangzhou, China) at $42^{\circ} \mathrm{C}$ for $1 \mathrm{~h}$. PCR amplification was performed in $20 \mu \mathrm{l}$ of $\mathrm{PCR}$ reaction mixture containing
$1 \mu \mathrm{l}$ of the cDNA reaction mixture, $10 \mathrm{nmol}$ of the $\mathrm{dNTP}$ mixture, $10 \mathrm{pmol}$ of the upstream and downstream primers and 2 units of BioReady rTaq polymerase (Bioer). The PCR amplification method to detect differences among the samples was set as follows: $4 \mathrm{~min}$ at $94^{\circ} \mathrm{C}$ for initial denaturation; 35 cycles $x 1 \mathrm{~min}$ at $94^{\circ} \mathrm{C}, 45 \mathrm{sec}$ at $53^{\circ} \mathrm{C}$ and $50 \mathrm{sec}$ at $72^{\circ} \mathrm{C}$ for Bcl-2; 30 cycles x $1 \mathrm{~min}$ at $94^{\circ} \mathrm{C}, 45 \mathrm{sec}$ at $52^{\circ} \mathrm{C}$, and $1 \mathrm{~min}$ at $72^{\circ} \mathrm{C}$ for Bax; and 30 cycles x $30 \mathrm{sec}$ at $94^{\circ} \mathrm{C}, 30 \mathrm{sec}$ at $54^{\circ} \mathrm{C}$, and $1 \mathrm{~min}$ at $72^{\circ} \mathrm{C}$ for GAPDH. The primers used for PCR were as follows: Bcl-2 (200 bp): forward, 5'-GAA GGA ATG TTG CAT GAG TCG GAT C-3' and reverse, 5'-AAG GGA ACT GCG GAT GTA AAG ATC C-3'; Bax (146 bp): forward, 5'-TTT TGC TTC AGG GTT TCA TC-3' and reverse, 5'-GTT CTT CGA CTC GCT CAC AG-3'; GAPDH (230 bp): forward, 5'-GTG GAA TCA TAT TGG AAC ATG T-3' and reverse, 5'-CTC TCT GCT CCT CCT GTT CGA CAG-3'. For the analysis of PCR products, $5 \mu \mathrm{l}$ of PCR products from each sample were electrophoresed on a $1.5 \%$ agarose gel containing $0.1 \mu \mathrm{g} / \mathrm{ml}$ dye (GoldView, SBS Genetech, Beijing, China). Gels were visualized and photographed by a Gel-Doc image analyzer (Bio-Rad, Hercules, CA, USA). The housekeeping gene GAPDH was used for normalization to evaluate relative changes in the mRNA expression levels of the examined genes, and the band intensity was analyzed with the ImageJ system (NIH, USA).

Preparation of nuclear extracts and Western blot analysis. JEG-3 cells were washed twice with ice-cold PBS and scraped into $1 \mathrm{ml}$ of the same buffer. After centrifugation at $1,000 \mathrm{x} \mathrm{g}$, the cell pellet was suspended in ice-cold hypotonic lysis buffer (10 mM HEPES pH 7.9, 0.2 mM KCl, $1.5 \mathrm{mM} \mathrm{MgCl}{ }_{2}, 0.5 \mathrm{mM}$ dithiothreitol, $0.2 \mathrm{mM}$ phenylmethylsulphonylfluoride), vortexed for $10 \mathrm{sec}$ and then centrifuged at 12,000 x $\mathrm{g}$ for $5 \mathrm{~min}$. The packed cells were suspended in ice-cold hypotonic lysis buffer in the presence of $50 \mu \mathrm{l}$ of $10 \%$ Nonidet P-40 and then kept on ice for $25 \mathrm{~min}$. The nuclear fraction was precipitated by centrifugation at $12,000 \mathrm{x} \mathrm{g}$ for $15 \mathrm{~min}$. The supernatants, corresponding to the cytosolic fraction, were transferred into fresh tubes and assayed for protein content by the Bradford method (Bradford, 1976). The nuclei pellet was resuspended in $70 \mu \mathrm{l}$ of low-salt extraction buffer (20 mM HEPES pH 7.9, $20 \mathrm{mM} \mathrm{KCl}, 1.5 \mathrm{mM} \mathrm{MgCl}_{2}, 0.2 \mathrm{mM}$ EDTA, 25\% glycerol, $0.2 \mathrm{mM}$ phenylmethylsulphonylfluoride, $0.5 \mathrm{mM}$ dithothreitol) and added to an equal volume of high-salt extraction buffer (20 mM HEPES pH 7.9, $80 \mathrm{mM} \mathrm{KCl,} 1.5 \mathrm{mM} \mathrm{MgCl} \mathrm{mg}_{2}, 0.2 \mathrm{mM}$ EDTA, $25 \%$ glycerol, $0.2 \mathrm{mM}$ phenylmethylsulphonylfluoride, $0.5 \mathrm{mM}$ dithothreitol) in a dropwise fashion, and then incubated under continuous shaking at $4^{\circ} \mathrm{C}$ for $45 \mathrm{~min}$. The sample was centrifuged for $20 \mathrm{~min}$ at $12,000 \mathrm{x} \mathrm{g}$. The nuclear extract was aliquoted and stored at $-80^{\circ} \mathrm{C}$. Then, $50 \mu \mathrm{g}$ of protein were loaded per lane onto $12-15 \%$ SDS-polyacrylamide gels. The proteins were separated and transferred to 0.45 or $0.22 \mu \mathrm{m}$ polyvinylidene fluoride membranes. Membranes were blocked with 5\% skim milk in PBS with $0.1 \%$ Tween-20 (PBST) for 1 h. Primary antibodies against human NF- $\kappa B$, p38, p-p38, ERK1/2, p-ERK1/2, Akt, p-Akt, caspase-3, Bcl-2, Bax and $\beta$-actin in PBST were incubated with the membranes overnight at $4^{\circ} \mathrm{C}$. The membranes were then washed in PBST thrice and incubated with HRP-conjugated secondary antibodies for $1 \mathrm{~h}$. After the final wash, protein bands were developed using 
A

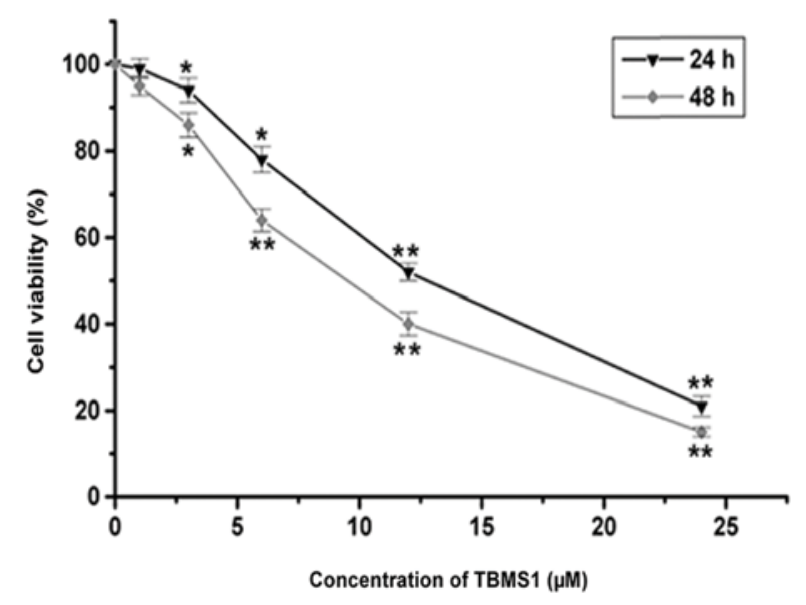

C
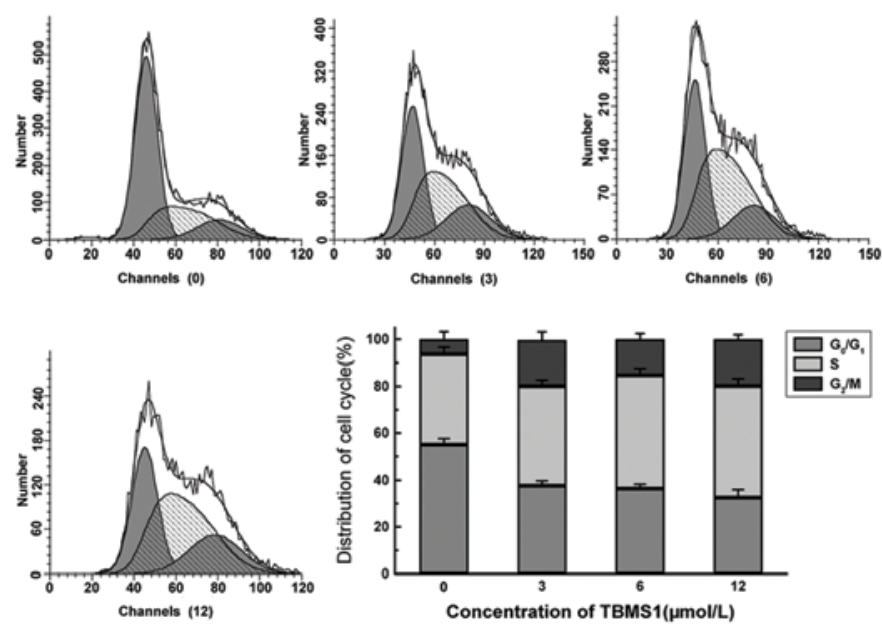

B

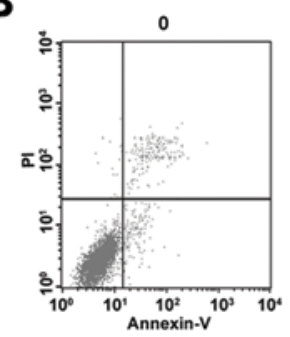

12
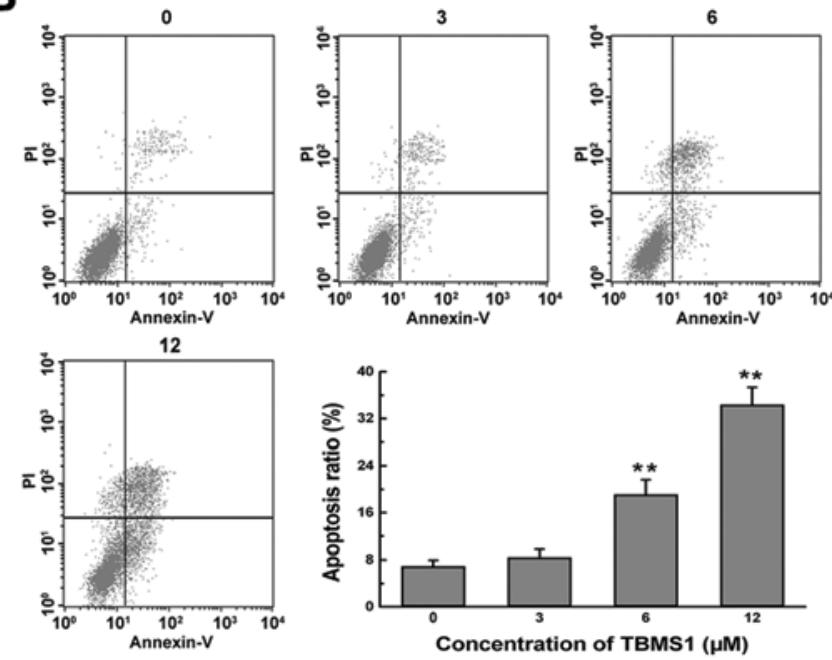

D

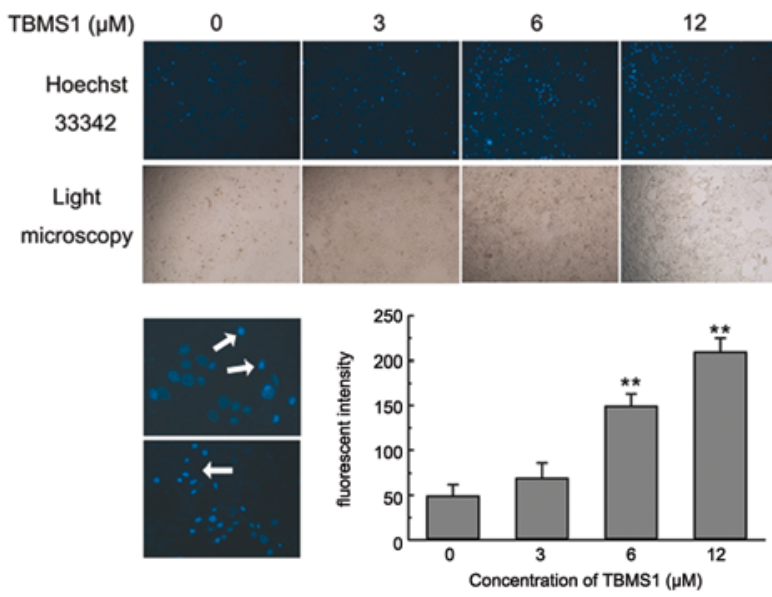

Figure 2. TBMS1-induced apoptosis in JEG-3 cells. (A) Cells were treated with TBMS1 (1 to $24 \mu \mathrm{M}$ ) for 24 or $48 \mathrm{~h}$, and cell viability assays were performed using the MTT method as described under Materials and methods. (B) Cells treated with TBMS1 (3, 6 and $12 \mu \mathrm{M})$ for $24 \mathrm{~h}$ were harvested and labeled with a combination of PI and Annexin V-FITC, and analyzed by flow cytometry. (C) Cells were treated with TBMS1 (3, 6 and $12 \mu \mathrm{M})$ for 24 h. The cell cycle distribution was analyzed by flow cytometry. (D) Morphological alterations of JEG-3 cells treated with TBMS1 (3, 6 and $12 \mu$ M) for 24 h were visualized by fluorescence microscopy (x10) of cells that were stained with Hoechst 33342. Data are expressed as the mean $\pm \mathrm{SD}$ of three determinations. ${ }^{*} \mathrm{P}<0.05$, ${ }^{* *} \mathrm{P}<0.01$, compared to the vehicle-treated control group.

enhanced chemiluminescence reagents, and densitometric analysis was performed using the PDI Imageware System (Bio-Rad).

Statistics. Statistical analyses were performed using the SPSS 10.0 package (SPSS Inc., Chicago, IL, USA). Data were expressed as the mean \pm S.D. of 3-5 independent experiments. ANOVA and Student's t-test were performed to determine the statistical significance. Differences between groups were considered to be significant at $\mathrm{P}<0.05$ or $\mathrm{P}<0.01$.

\section{Results}

TBMS1 induced apoptosis in JEG-3 cells. The growth inhibition of JEG-3 cells by TBMS1 was observed by the MTT assay following treatment of different doses of TBMS1 for the times indicated. As shown in Fig. 2A, gradual losses of cell viability were observed with increased concentrations of TBMS1, and the estimated $\mathrm{IC}_{50}$ value was $8.5 \mu \mathrm{M}$ after $24 \mathrm{~h}$ of treatment.
The results indicated that TBMS1 displays strong growth inhibition of JEG-3 cells in a dose-dependent manner. Whether the proliferation inhibition induced by TBMS1 in JEG-3 cells is associated with apoptosis or cell lysis is still not clear.

In order to quantitatively assess gain insight into the proapoptotic effects of TBMS1, a display of PI vs. Annexin V-FITC fluorescence was measured by flow cytometric analysis. The appearance of cells with a high Annexin signal and a low PI signal is characteristic of early apoptosis. The progression of apoptosis results in cells with a high Annexin signal and a high PI signal characteristic of late apoptosis (secondary necrosis). In the control group, $7.6 \pm 0.9 \%$ cells excluded PI and were positive for Annexin V-FITC binding, representing apoptotic cells. After exposure to TBMS1 (3, 6 and $12 \mu \mathrm{M})$ for $24 \mathrm{~h}$, the percentage of apoptosis increased to $8.5 \pm 0.8$, $19.1 \pm 4.4$ and $34.4 \pm 3.0 \%$, respectively (Fig. $2 \mathrm{~B}$ ). To investigate the mechanism of TBMS1 on JEG-3 cells, flow cytometry analysis was carried out to detect the changes in the cell cycle distribution. Results showed that treatment of the cells with 
A

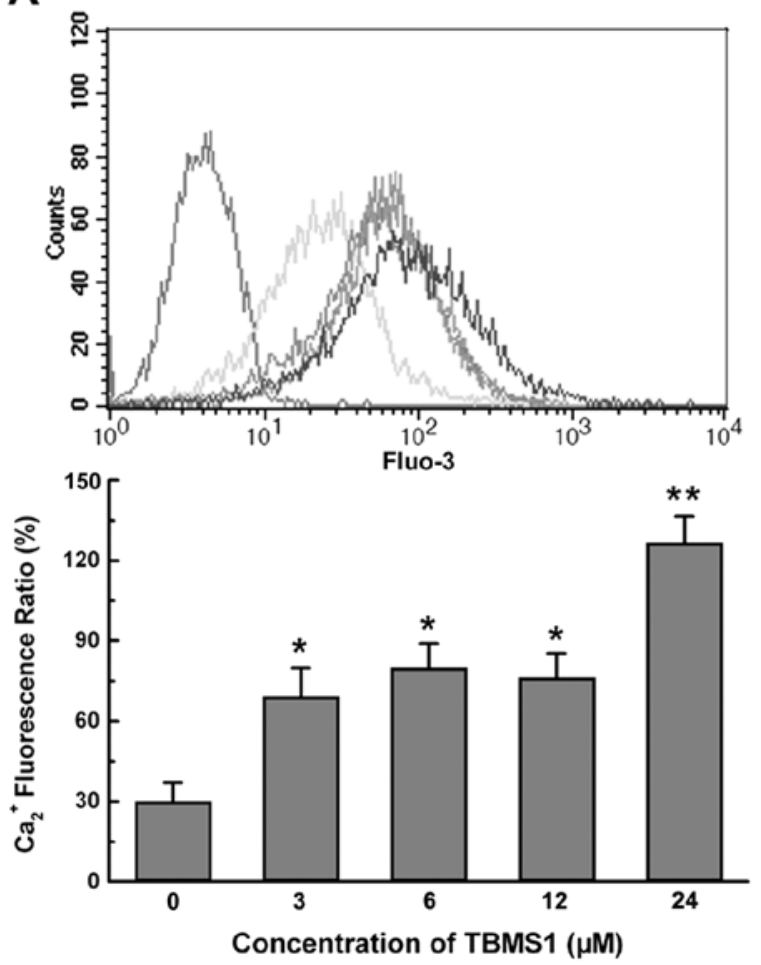

B
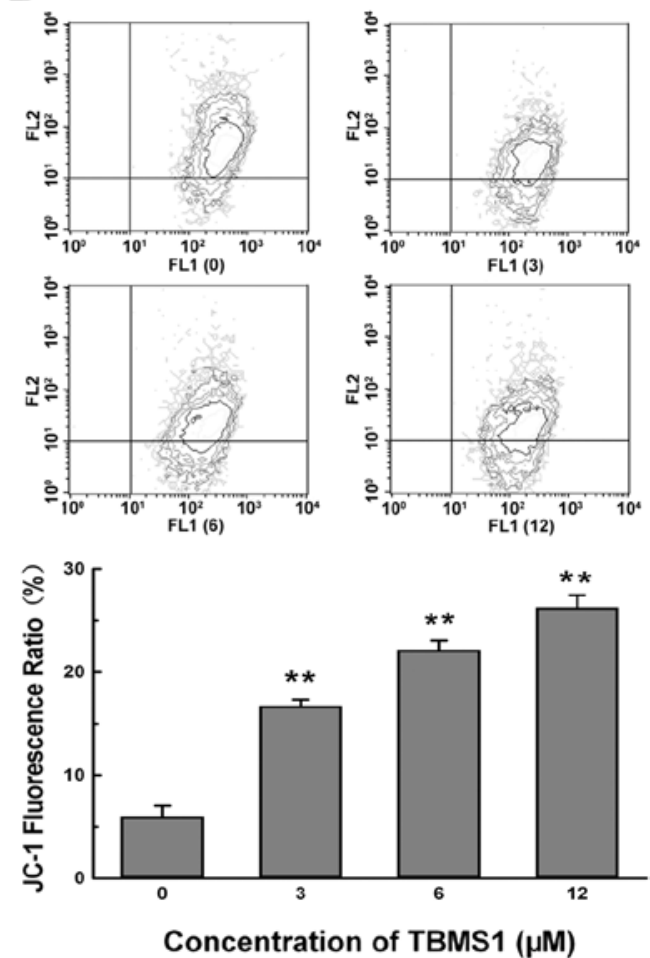

Figure 3. Increase of intracellular $\mathrm{Ca}^{2+}$ levels and dissipation of mitochondrial transmembrane potential occurs in JEG-3 cells after exposure to TBMS1. (A) Cells were treated with TBMS1 $(3,6,12$ and $24 \mu \mathrm{M})$ for $24 \mathrm{~h}$. Levels of intracellular Ca ${ }^{2+}$ in JEG-3 cells were measured by the fluo-3 dye using flow cytometry. (B) Cells were treated with TBMS1 $(3,6$ and $12 \mu \mathrm{M})$ for $24 \mathrm{~h}$, stained with JC-1 and measured by flow cytometry. Each value is the mean \pm SD of three determinations. ${ }^{*} \mathrm{P}<0.05,{ }^{* *} \mathrm{P}<0.01$, compared to the vehicle-treated control group.

different concentrations of TBMS1 for $24 \mathrm{~h}$ induced $\mathrm{G}_{2} / \mathrm{M}$ phase arrest, when the percentages of cells in the $\mathrm{S}$ phase decreased (Fig. 2C).

To confirm the function of TBMS1-induced apoptosis, morphological analyses of cell characteristics were observed under the fluorescence microscope by Hoechst 33342 staining. Compared to the control group $(50.3 \pm 12.1 \%)$, the quantity of positive cells increased significantly $(210.7 \pm 14.8 \%)$ after treatment with TBMS1 $(12 \mu \mathrm{M})$. Accordingly, chromatin condensation and nuclear fragmentation typical for apoptosis induction were visualized (Fig. 2D).

TBMS1 causes mitochondrial dysfunction. The development of apoptosis was shown to be associated with an increase of cytosolic $\mathrm{Ca}^{2+}$, which subsequently leads to mitochondrial depolarization and initiates a cell death cascade (16-18). Whether or not the TBMS1-induced apoptosis in JEG-3 cells is regulated by the mitochondrial dysfunction pathway is not known. The involvement of the cytosolic $\mathrm{Ca}^{2+}$ store was examined first. Cells were loaded with the calcium probe fluo-3. There was a significant increase $(126.6 \pm 9.8 \%)$ in the levels of intracellular $\mathrm{Ca}^{2+}$ in JEG-3 cells after treatment with TBMS1 compared with the untreated controls $(30.1 \pm 7.1 \%)$ (Fig. 3A).

Mitochondrial $\mathrm{Ca}^{2+}$ overload in response to a cytosolic $\mathrm{Ca}^{2+}$ increase is known to lead to the opening of the MPTP (PT-pore). A sequelae and indicator of PT-pore opening is the depolarization of the mitochondrial membrane (18). Mitochondrial membrane potential was assessed by fluorescent probe JC-1 using flow cytometry. Results showed that the mitochondrial membrane potential was reduced after $24 \mathrm{~h}$ of TBMS1-treatment, as assessed by the increase in fluorescence of JC-1 (4-fold higher compared to controls) (Fig. 3B).

The opening of the PT-pore and depolarization of the mitochondrial membrane induced cytochrome c release from the mitochondrial intermembraneous space into the cytosol, which is a prominent downstream manifestation of the evolution of apoptotic cell death (19). Movement of cytochrome c was then examined by immunofluorescence using confocal microscopy. Cytochrome $\mathrm{c}$ is localized in the mitochondria around the nucleus in normal cells, and the fluorescence is distributed in a ring-shape (Fig. 4). After stimulation with TBMS1, the cytochrome c fluorescence apparently diffused into the cytoplasm, which demonstrates the movement of cytochrome $\mathrm{c}$ induced by TBMS1. Caspase-3 normally exists as a $35 \mathrm{kDa}$ inactive precursor. It is converted proteolytically into a $17 \mathrm{kDa}$ active heterodimer when the cells are signaled to undergo apoptosis (20). Caspase-3 activation was also measured by Western blot analysis. Cells in the control group showed minimal expression of active caspase-3, which was remarkably induced by TBMS1 (Fig. 5A). All of the above indicate that the apoptosis of JEG-3 cells induced by TBMS1 was regulated by the induction of mitochondrial dysfunction, at least in part.

Effect of TBMS1 on the activation of proteins from the Bcl-2 family. The Bcl-2 family, whose members may be antiapoptotic or pro-apoptotic, regulates cell death by controlling mitochondrial membrane permeability as an arbiter of the mitochondrial apoptotic pathway (21-23). In our study, we 


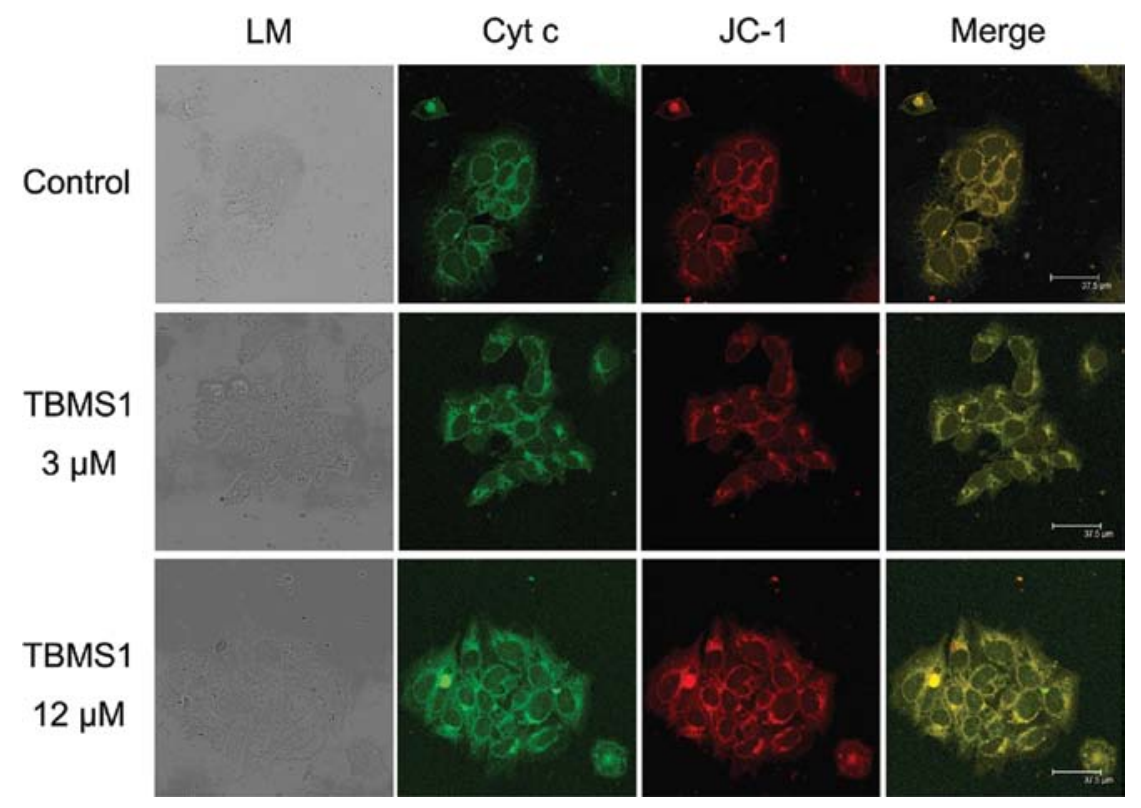

Figure 4. Release of cytochrome $\mathrm{c}(\mathrm{Cyt} \mathrm{c})$ into the cytosol following TBMS1 treatment. Representative immunofluorescence images of cytochrome $\mathrm{c}$ localization in JEG-3 cells treated for $24 \mathrm{~h}$ with TBMS1 ( 3 and $12 \mu \mathrm{M}$ ). The staining for anti-cytochrome c-FITC and JC-1 are indicated by green and red fluorescence, respectively. Each value is the mean $\pm \mathrm{SD}$ of three determinations.

found that the expression of Bax was strongly up-regulated at the mRNA (4-fold $>$ than controls) and protein levels (10-fold $>$ than controls) in JEG-3 cells pre-treated with TBMS1 (3, 6 and $12 \mu \mathrm{M})$ for $24 \mathrm{~h}$. In contrast, the expression of Bcl-2 was significantly down-regulated (3-fold < compared to control) (Fig. 5B and C). These results may suggest that the proteins of the Bcl-2 family play a critical role in TBMS1induced mitochondrial dysfunction.

Inhibitory effects of TBMSI on nuclear factor $\kappa B(N F-\kappa B)$ translocation and activation. Recent evidence in another cellular system suggested that Bcl-2 expression may involve direct transcriptional activation through $\mathrm{NF}-\kappa \mathrm{B}$ (24). To investigate whether a similar mechanism could be operational in choriocarcinoma JEG-3 cells, we first analyzed luciferase reporter constructs containing the NF- $\mathrm{KB}$ promoter, which was markedly inhibited after TBMS1 $(6 \mu \mathrm{M})$ treatment; quantification of fluorescence data decreased to $0.7 \pm 0.2 \%$ compared with the controls $(2.3 \pm 0.3 \%)$ (Fig. 5D). In addition, we performed the NF- $\mathrm{KB}$ translocation experiment. The data in Fig. 5E demonstrate that, after being exposed to TBMS1 (3, 6 and $12 \mu \mathrm{M}$ ) for $24 \mathrm{~h}, \mathrm{NF}-\mathrm{kB}$ p65 proteins showed an explosive decrease in the nucleus and a pronounced increase in the cytoplasm. All data indicate that TBMS1 effectively attenuated the NF- $\kappa$ B activation and translocation in JEG-3 cells.

TBMS1 induced the activation of $p 38 / M A P K$ and inhibition of ERK1/2 and PI3K/Akt in JEG-3 cells. Because a pivotal role for $\mathrm{NF}-\mathrm{\kappa B}$ in the regulation of cell survival and death is suggested, recent reports have attempted to identify the upstream regulators of NF- $\mathrm{KB}$ to reveal the involvement of p38/MAPK, ERK1/2 and PI3K/Akt (25-28). We hypothesized that TBMS1 may modulate these signaling pathways. Employing Western blot analysis, we investigated the effect of TBMS1, for $24 \mathrm{~h}$ at all concentrations tested, on the levels of constitutively expressed p38/
MAPK, ERK1/2 and Akt proteins in JEG-3 cells, by Western blot analysis. We observed high levels of p38/MAPK phosphorylation (almost 160-fold higher compared with the control groups) (Fig. 5F-H). In contrast, low levels of ERK1/2 and Akt phosphorylation (only one-sixth of that of the control groups) were presented. Therefore, we can speculate that TBMS1 may act through the p38/MAPK, ERK1/2 and PI3K/Akt pathways.

\section{Discussion}

It is a major challenge to identify new targets for anticancer drugs and the synthesis of new anticancer drugs in tumor therapy. Apoptosis, a process that removes unwanted or damaged cells, plays a pivotal role in tissue homeostasis; once disrupted, the outcome is the formation of tumors (9). Most chemotherapy agents aim for the specific eradication of cancer cells and also result in the induction of apoptosis.

Mitochondria have not only long been known as cellular 'power plants', but are also key participants in several cell death pathways. Most tumor cells are characterized predominately by glycolytic production of ATP, which is often associated with perturbations of mitochondrial functions and resistance to cell death triggers (29). Thus, the design of mitochondrion-targeted cytotoxic drugs may constitute a novel strategy for cancer chemotherapy. A large number of toxins, such as lonidamine, arsenite, betulinic acid and L-carnitine, inhibit the respiratory function of mitochondria and/or stimulate futile redox cycles, thereby inducing cell death (30). TBMS1, a traditional Chinese herbal medicine isolated from the tubers of Bolbostemma paniculatum, showed antitumor-promoting effects $(4,6,7)$. It was suggested that the target of TBMS1 may be the mitochondria. However, the mechanism of TBMS1 in regulating mitochondrial malfunction and apoptosis remains unclear.

Our study revealed that the proliferation of human choriocarcinoma JEG-3 cells was markedly inhibited by TBMS1, 
A
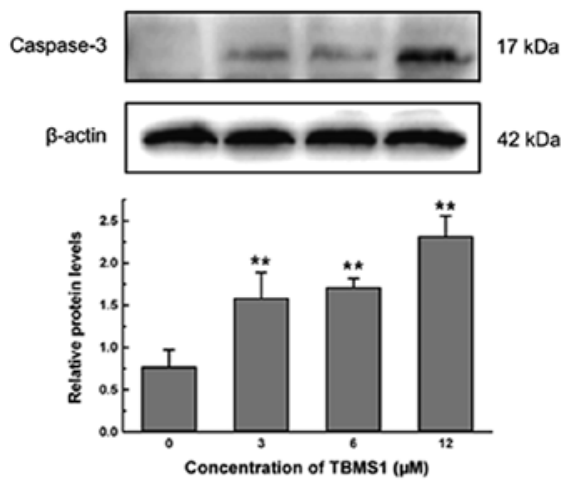

D

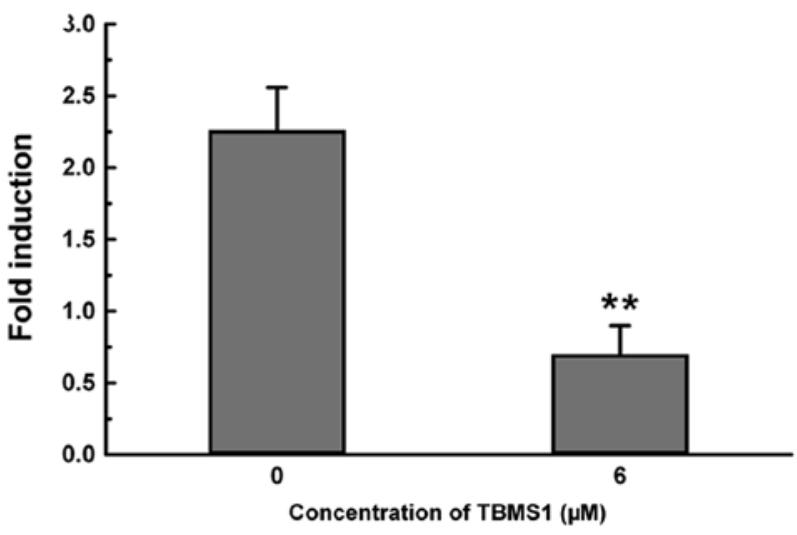

B

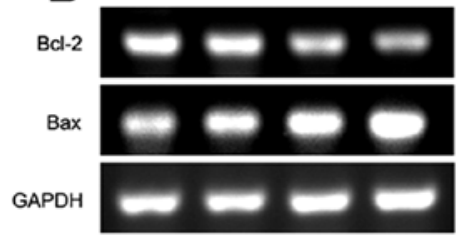

$200 \mathrm{bp}$

$146 \mathrm{bp}$

$230 \mathrm{bp}$
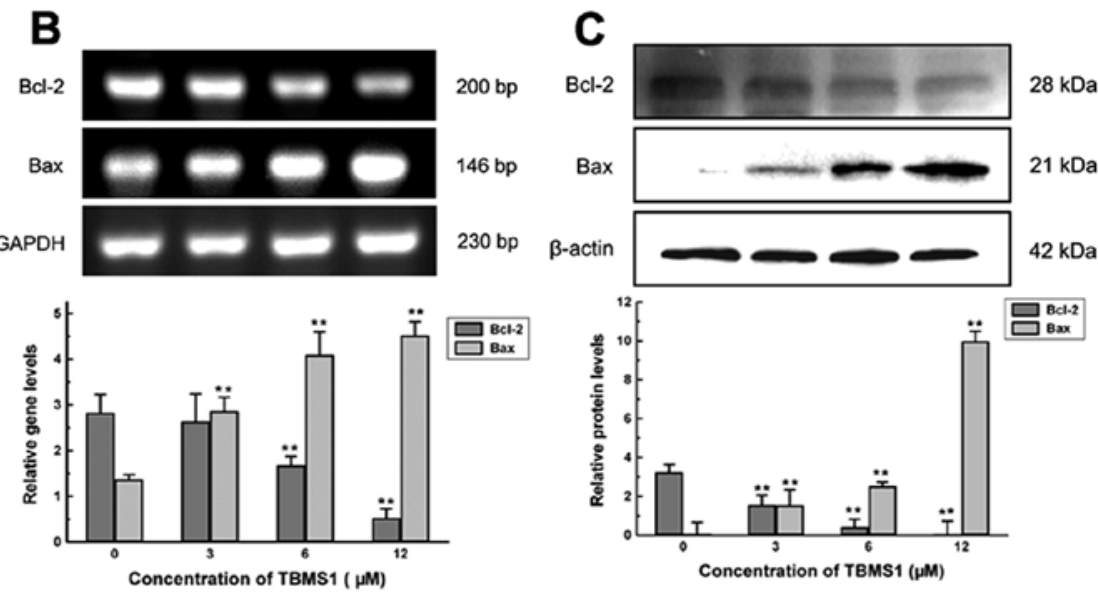

$\mathbf{E}$
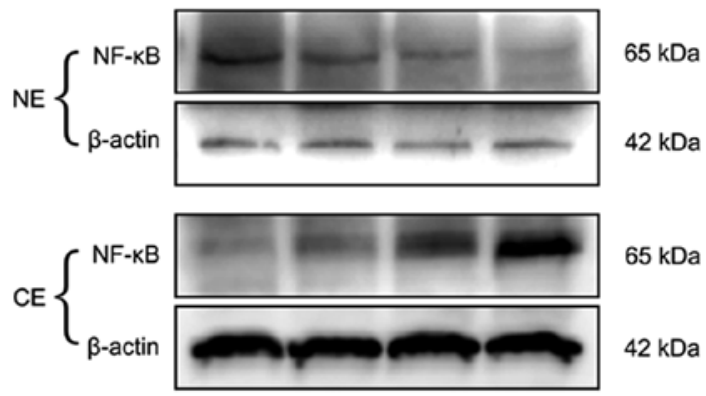

$65 \mathrm{kDa}$

42 kDa

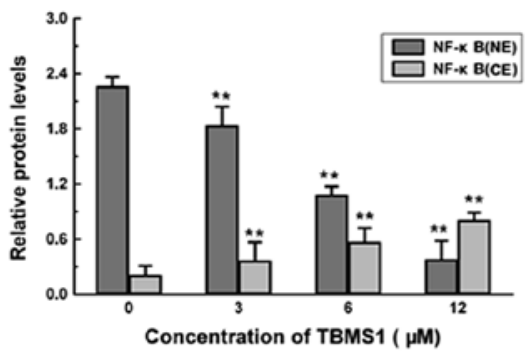

$\mathbf{F}$
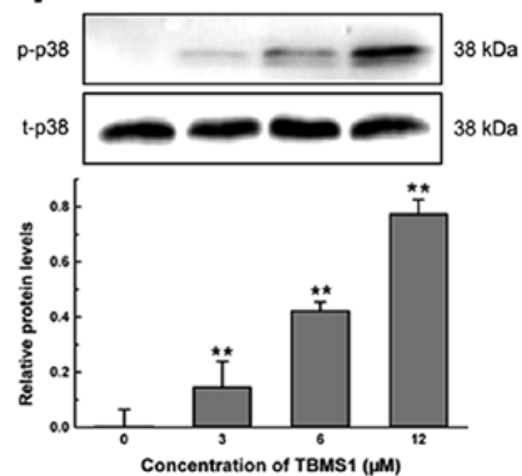

G
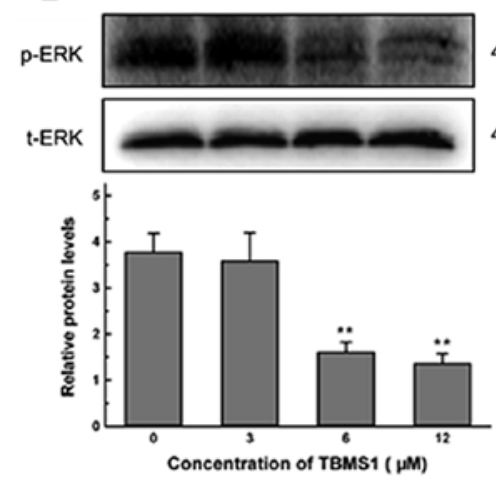

H
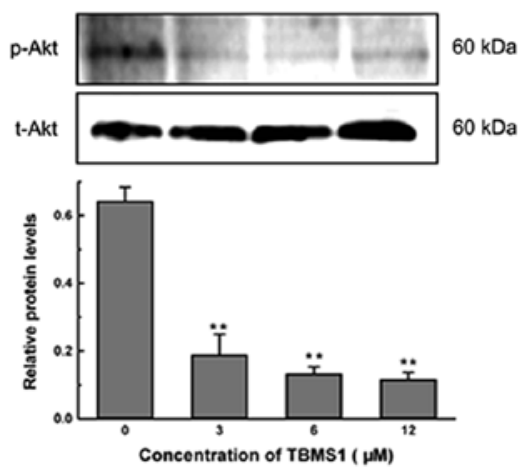

Figure 5. Effects of TBMS1 on the mitochondria-related signaling pathway. Cells were pre-treated with TBMS1 (3, 6 and $12 \mu \mathrm{M})$ for 24 h. After treatment, cells were extracted, and the mRNA level of Bcl-2 and Bax (B) were determined by RT-PCR analysis as described in the Materials and methods section. The protein levels of cleaved caspase-3 (A), Bcl-2 and Bax (C), phosphorylated p38/MAPK (p-p38) and total p38/MAPK (t-p38) (F), phosphorylated ERK1/2 (p-ERK1/2) and total ERK1/2 (t-ERK1/2) (G), and phosphorylated Akt (p-Akt) and total Akt (t-Akt) (H) were determined by Western blot analysis as described in Materials and methods. (D) Cells were co-transfected with the pNF- $\kappa \mathrm{B}$ and pLR-TK luciferase reporter vectors, and then treated for $24 \mathrm{~h}$ with TBMS1 $(6 \mu \mathrm{M})$. Luciferase activity was expressed as the fold-induction of respective controls. (E) Cells were pre-treated with TBMS1 (3, 6 and $12 \mu \mathrm{M})$ for $24 \mathrm{~h}$. After treatment, nuclear (NE) and cytoplasmic (CE) fractions were analyzed for detection of NF- $\kappa \mathrm{B}$ by Western blot analysis. All data are presented as histograms. Each value is the mean $\pm \mathrm{SD}$ of three determinations. ${ }^{*} \mathrm{P}<0.05,{ }^{* *} \mathrm{P}<0.01$, compared to the vehicle-treated control group.

which was implemented by cell apoptosis and cell cycle arrest. Apoptosis is characterized by cell shrinkage, membrane blebbing, nuclear pyknosis, chromatin condensation and genomic fragmentation (31), which could be observed after the nuclei were stained by Hoechst 33342. DNA replication is controlled by cyclins. For example, cyclin A is synthesized and localized in the nucleus at the onset of the $S$ phase (32), and the cyclin D protein is required for the $G_{1}$ phase (33). We found that TBMS1 


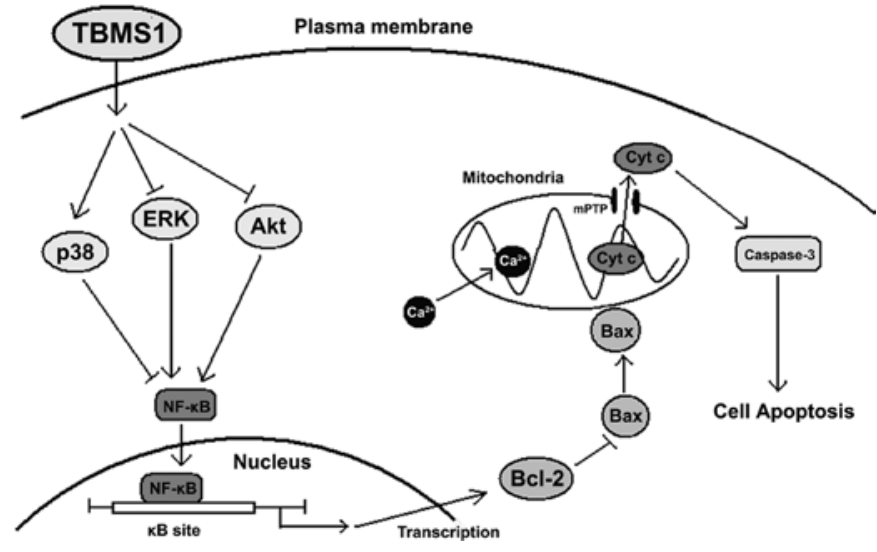

Figure 6. The hypothetical schematics of tubeimoside I-induced apoptosis in human choriocarcinoma JEG-3 cells. The schematic representation shows that TBMS1 induces apoptosis in JEG-3 cells by attenuating the NF- $\kappa \mathrm{B}$ activation and translocation through the MAPK/p38, ERK1/2 and PI3K/Akt pathways, breaking the balance of $\mathrm{Bax} / \mathrm{Bcl}-2$, aggravating mitochondria dysfunction, releasing cytochrome $\mathrm{c}$ and regulating caspases-3 activation.

was capable of increasing cyclin D and decreasing cyclin A concentrations (data are not shown). This result was consistent with the flow cytometry analysis.

One of the key events in early apoptosis is the permeabilization of the mitochondrial membrane, which includes the permeabilization of the inner mitochondrial membrane (IMM), the OMM, or both (34). In the case of IMM permeabilization, the principal mechanism involved is the opening of the mPTP. Once $\mathrm{Ca}^{2+}$ is released from the ER into the cytoplasm, mitochondria take up part of the released $\mathrm{Ca}^{2+}$ to prevent the propagation of large calcium waves (35). To meet the increasing energy demands of the cell, physiological increases in mitochondrial $\mathrm{Ca}^{2+}$ concentration induces increased activity of the mitochondrial respiratory chain and the synthesis of ATP. Pathological overload of calcium in the mitochondria triggers the opening of the MPTP, which leads to mitochondrial dysfunction (36). In our study, accumulation of $\mathrm{Ca}^{2+}$ in the cytoplasm and depolarization of the mitochondrial membrane were detected when the cells were exposed to TBMS1, which suggested that the pro-apoptotic effect of TBMS1 may be regulated by the induction of mitochondrial dysfunction. In the case of OMM permeabilization, the $\mathrm{Bcl}-2$ family of cell death regulators, found as the monomeric form in the cytosol, or loosely attached to the membranes under normal conditions, plays a key role. Upon induction of apoptosis, members of the pro-apoptotic Bcl-2 family, such as monomeric Bax, translocates to the outer membrane of the mitochondria where it becomes an integral membrane protein and is crosslinkable as a homodimer. This decreases the mitochondrial membrane permeability and results in the release of mitochondrial apoptogenic factors, such as cytochrome c, to propagate the apoptotic pathway. In contrast, the anti-apoptotic factor Bcl-2 prevents the oligomerization of Bax in the OMM and pore formation (34-38). Once released from the mitochondria, cytochrome $\mathrm{c}$ binds to the apoptosis protease activation factor (Apaf-1) and forms a complex called the 'apoptosome', which triggers the activation of caspase-3, which leads to apoptosis $(39,40)$. As expected, treatment of JEG-3 cells with TBMS1 significantly increased the expression of Bax and decreased the expression of Bcl-2. In addition, multiplication of cytochrome $\mathrm{c}$ in the cytosol and activation of caspase- 3 are also observed, which is consistent with previous reports $(39,40)$.

Expression of anti-apoptotic genes (Bcl-2) is regulated by transcription factors such as NF- $\kappa \mathrm{B}$, a ubiquitous and evolutionarily conserved transcription factor, and is significantly activated in a great number of tumors (41). NF- $\kappa \mathrm{B}$ was found to up-regulate anti-apoptotic gene expression and therefore disrupted the balance between apoptosis and proliferation (42). The most abundant form of NF- $\kappa \mathrm{B}$ is the heterodimer of p50 and p65. The p65 subunit is responsible for transcriptional activity (43). It has been reported that activated NF- $\kappa$ B blocks cellular apoptosis in several different cell types (42). Upon activation, NF- $\kappa \mathrm{B}$ proteins translocate from the cytoplasm into the nucleus and bind to promoters of target genes, including $\mathrm{Bcl}-2$, to initiate the production of various mediators (24). Attenuation of the NF- $\kappa \mathrm{B}$ activation and translocation under the stimulation of TBMS1, as demonstrated in our study, may suggest that the inactivation of $\mathrm{NF}-\kappa \mathrm{B}$ caused the cells to be more sensitive to TBMS1; however, the details of the molecular mechanism needs to be further explored.

To elucidate the potential mechanisms leading to the inhibition of NF- $\kappa \mathrm{B}$ activation by TBMS1, we explored the signaling cascades, including two distinct types of MAPKs (p38/MAPK and ERK1/2) and PI3K/Akt, which are known to act as upstream intermediates that provide a link between extracellular stimuli and NF- $\kappa \mathrm{B}$ in various cell lines $(28,31,32)$. The pro-survival oncoproteins Akt (also known as PKB) and ERK1/2 have been found to promote cell survival through the activation of NF- $\mathrm{BB}$ (27), while p38/MAPK facilitates cell apoptosis (44). Our results suggested that the inhibition of the NF- $\kappa$ B pathway could be mediated by promotion of p38/MAPK phosphorylation and inhibition of ERK1/2 and Akt phosphorylation. However, future studies may be needed to determine the mechanism.

In this study, we demonstrated for the first time, to our knowledge, that TBMS1 has an antitumor effect on human choriocarcinoma cells. We also provided novel evidence to show that the mechanism of the pro-apoptotic effect of TBMS1 is mediated through the mitochondrial dysfunction pathway, which depends on the regulation of $N F-\kappa B$ and of proteins of the Bcl-2 family. We have also found that, in addition, TBMS1 affects the p38/MAPK, ERK1/2 and PI3K/Akt pathways (our hypothetical schematics are shown in Fig. 6). Considering the pronounced anti-apoptotic effects of TBMS1 on JEG-3 cells, our studies provide novel insight into the future therapeutic applications of TBMS1 in cancer treatment.

\section{Acknowledgements}

We are grateful for the financial support from the National Nature Science Foundation of China (project no. 81070222), the Nature Science Foundation of Chongqing (project no. CSTC, 2009BA5083) and the Key Foundation of Chongqing Medical University (project no. XBED 200806).

\section{References}

1. Caroppi P, Sinibaldi F, Fiorucci L and Santucci R: Apoptosis and human diseases: mitochondrion damage and lethal role of released cytochrome $\mathrm{C}$ as proapoptotic protein. Curr Med Chem 16: 4058-4065, 2009. 
2. Kluck RM, Bossy-Wetzel E, Green DR and Newmeyer DD: The release of cytochrome $\mathrm{c}$ from mitochondria: a primary site for Bcl-2 regulation of apoptosis. Science 275: 1132-1136, 1997.

3. Green DR and Reed JC: Mitochondria and apoptosis. Science 281: 1309-1312, 1998

4. Hengartner MO: The biochemistry of apoptosis. Nature 407: $770-776,2000$

5. Kuwana T and Newmeyer DD: Bcl-2-family proteins and the role of mitochondria in apoptosis. Curr Opin Cell Biol 15: 691-699, 2003.

6. Nicholson DW and Thornberry NA: Apoptosis. Life and death decisions. Science 299: 214-215, 2003.

7. Kong FH,Zhu DY, Xu RS, et al: Structural study of tubeimoside I, a constituent of tu-bei-mu. Tetrahedron Letter 27: 5765-5768, 1986.

8. Yu LJ, Ma RD, Wang YQ, et al: Potent anti-tumorigenic effect of tubeimoside 1 isolated from the bulb of Bolbostemma paniculatum (Maxim) Franquet. Int J Cancer 50: 635-638, 1992.

9. Yu L, Ma R, Wang Y and Nishino H: Potent anti-tumor activity and low toxicity of tubeimoside 1 isolated from Bolbostemma paniculatum. Planta Med 60: 204-208, 1994.

10. Ma R, Song G, You W, et al: Anti-microtubule activity of tubeimoside I and its colchicine binding site of tubulin. Cancer Chemother Pharmacol 62: 559-568, 2008

11. Yu L, Ma R and Yu T: Induction of morphological and functional differentiation of human promyelocytic leukemia cells (HL-60) by Tubeimoside 1. Planta Med 62: 119-121, 1996.

12. Wang F, Ma R and Yu L: Role of mitochondria and mitochondrial cytochrome $\mathrm{c}$ in tubeimoside I-mediated apoptosis of human cervical carcinoma HeLa cell line. Cancer Chemother Pharmacol 57: 389-399, 2006

13. Mosmann T: Rapid colorimetric assay for cellular growth and survival: application to proliferation and cytotoxicity assays. J Immunol Methods 65: 55-63, 1983.

14. Hammill AK, Uhr JW and Scheuermann RH: Annexin V staining due to loss of membrane asymmetry can be reversible and precede commitment to apoptotic death. Exp Cell Res 251: 16-21, 1999.

15. Puissant $C$ and Houdebine LM: An improvement of the single-step method of RNA isolation by acid guanidinium thiocyanate-phenolchloroform extraction. Biotechniques 8: 148-149, 1990

16. Weiss JN, Korge P, Honda HM and Ping P: Role of the mitochondrial permeability transition in myocardial disease. Circ Res 93 292-301, 2003.

17. Gustafsson $A B$ and Gottlieb RA: Mechanisms of apoptosis in the heart. J Clin Immunol 23: 447-459, 2003.

18. Crow MT, Mani K, Nam YJ and Kitsis RN: The mitochondrial death pathway and cardiac myocyte apoptosis. Circ Res 95: 957-970 2004

19. Degli Esposti M and Dive C: Mitochondrial membrane permeabilisation by Bax/Bak. Biochem Biophys Res Commun 304: 455-461, 2003.

20. Schlegel J, Peters I, Orrenius S, et al: CPP32/apopain is a key interleukin 1 beta converting enzyme-like protease involved in Fas-mediated apoptosis. J Biol Chem 271: 1841-1844, 1996.

21. Adams JM and Cory S: The Bcl-2 protein family: arbiters of cell survival. Science 281: 1322-1326, 1998.

22. Shimizu S, Narita $M$ and Tsujimoto $Y$ : Bcl-2 family proteins regulate the release of apoptogenic cytochrome $\mathrm{c}$ by the mitochondrial channel VDAC. Nature 399: 483-487, 1999.

23. Tsujimoto $\mathrm{Y}$ and Shimizu S: VDAC regulation by the Bcl-2 family of proteins. Cell Death Differ 7: 1174-1181, 2000.

24. Gupta SC, Prasad S, Reuter S, et al: Modification of cysteine 179 of IkappaBalpha kinase by nimbolide leads to down-regulation of NF-kappaB-regulated cell survival and proliferative proteins and sensitization of tumor cells to chemotherapeutic agents. J Biol Chem 285: 35406-35417, 2010.
25. Ozes ON, Mayo LD, Gustin JA, Pfeffer SR, Pfeffer LM and Donner DB: NF-kappaB activation by tumour necrosis factor requires the Akt serine-threonine kinase. Nature 401: 82-85, 1999.

26. Karin M and Lin A: NF-kappaB at the crossroads of life and death. Nat Immunol 3: 221-227, 2002.

27. Zhu Y, Culmsee C, Klumpp S and Krieglstein J: Neuroprotection by transforming growth factor-beta1 involves activation of nuclear factor-kappaB through phosphatidylinositol-3-OH kinase/Akt and mitogen-activated protein kinase-extracellular-signal regulated kinase1,2 signaling pathways. Neuroscience 123: 897-906, 2004.

28. Niranjan R, Nath C and Shukla R: The mechanism of action of MPTP-induced neuroinflammation and its modulation by melatonin in rat astrocytoma cells, C6. Free Radical Res 44: 1304-1316, 2010.

29. Simonnet H, Alazard N, Pfeiffer K, et al: Low mitochondrial respiratory chain content correlates with tumor aggressiveness in renal cell carcinoma. Carcinogenesis 23: 759-768, 2002.

30. Gogvadze V, Orrenius S and Zhivotovsky B: Mitochondria as targets for chemotherapy. Apoptosis 14: 624-640, 2009.

31. Rzepczynska IJ, Foyouzi N, Piotrowski PC, Celik-Ozenci C, Cress A and Duleba AJ: Antioxidants induce apoptosis of rat ovarian theca-interstitial cells. Biol Reprod 84: 162-166, 2010.

32. Girard F, Strausfeld U, Fernandez A and Lamb NJ: Cyclin A is required for the onset of DNA replication in mammalian fibroblasts. Cell 67: 1169-1179, 1991

33. Morgan DO: Cyclin-dependent kinases: engines, clocks, and microprocessors. Annu Rev Cell Dev Biol 13: 261-291, 1997.

34. Kroemer G, Galluzzi L and Brenner C: Mitochondrial membrane permeabilization in cell death. Physiol Rev 87: 99-163, 2007.

35. Jouaville LS, Ichas F, Holmuhamedov EL, Camacho P and Lechleiter JD: Synchronization of calcium waves by mitochondrial substrates in Xenopus laevis oocytes. Nature 377: 438-441, 1995.

36. Boitier E, Rea R and Duchen MR: Mitochondria exert a negative feedback on the propagation of intracellular $\mathrm{Ca}^{2+}$ waves in rat cortical astrocytes. J Cell Biol 145: 795-808, 1999.

37. Oltvai ZN, Milliman CL and Korsmeyer SJ: Bcl-2 heterodimerizes in vivo with a conserved homolog, Bax, that accelerates programmed cell death. Cell 74: 609-619, 1993.

38. Chipuk JE, Fisher JC, Dillon CP, Kriwacki RW, Kuwana T and Green DR: Mechanism of apoptosis induction by inhibition of the anti-apoptotic BCL-2 proteins. Proc Natl Acad Sci USA 105: 20327-20332, 2008.

39. Stennicke HR and Salvesen GS: Caspases - controlling intracellular signals by protease zymogen activation. Biochim Biophys Acta 1477: 299-306, 2000.

40. Liu X, Kim CN, Yang J, Jemmerson R and Wang X: Induction of apoptotic program in cell-free extracts: requirement for dATP and cytochrome c. Cell 86: 147-157, 1996.

41. Ricca A, Biroccio A, Del Bufalo D, Mackay AR, Santoni A and Cippitelli M: Bcl-2 over-expression enhances NF-kappaB activity and induces mmp-9 transcription in human MCF7(ADR) breast-cancer cells. Int J Cancer 86: 188-196, 2000.

42. Haefner B: NF-kappa B: arresting a major culprit in cancer. Drug Discov Today 7: 653-663, 2002.

43. Baldwin AS Jr: The NF-kappa B and I kappa B proteins: new discoveries and insights. Annu Rev Immunol 14: 649-683, 1996

44. Nizamutdinova IT, Oh HM, Min YN, et al: Paeonol suppresses intercellular adhesion molecule-1 expression in tumor necrosis factor-alpha-stimulated human umbilical vein endothelial cells by blocking p38, ERK and nuclear factor-kappaB signaling pathways. Int Immunopharmacol 7: 343-350, 2007. 